\title{
Otros modos de ver cine: nuevos espectadores y redes de cine independiente en México
}

\author{
ANTONIO ZIRIÓN PÉREZ
}

Este artículo ofrece un balance de los estudios antropológicos sobre consumos culturales, con énfasis en Latinoamérica. Se analiza el panorama emergente de la exhibición de cine independiente en la Ciudad de México, sobre todo documental, en festivales y cineclubes; se describen las estrategias creativas y redes de colaboración. En este marco, se plantea la necesidad de una investigación etnográfica sobre los nuevos espectadores de cine, que articule nociones y técnicas de varios campos de la antropología para dar testimonio de las modalidades de consumo audiovisual en la era digital. También se presenta el caso particular de una muestra de cine en la que se expresan los retos metodológicos y dilemas epistemológicos de los estudios sobre la cultura audiovisual contemporánea.

PALABRAS CLAVE: consumos culturales, cine independiente, festivales, espectadores, redes

Different Ways of Watching Films: New Spectators and Independent Cinema Networks in Mexico

This article reviews the state of cultural consumption studies from an anthropological perspective, focusing on Latin America. It analyses the emerging panorama of independent cinema exhibition in Mexico City, mainly of documentary films, in festivals and cinema clubs, describing their creative strategies and collaborative networks. In this framework, this paper points out the need for serious ethnographic research on new cinema spectators, articulating notions and techniques from different fields of anthropology in order to understand the new forms of audiovisual consumption in the digital era. The author presents a particular case of a film showcase, which is reveal-

ANTONIO ZIRIÓN PÉREZ

Universidad Autónoma MetropolitanaIztapalapa, Departamento de Antropología, Ciudad de México, México antoniozirion@gmail.com ing the methodological challenges and epistemological dilemmas involved in the study of contemporary visual culture.

KEYWORDS: cultural consumption, independent cinema, festivals, spectators, networks 


\section{Introducción}

1 tema de los consumos culturales resulta relevante para la antropología contemporánea porque invita a repensar algunas de las categorías y cuestiones más esenciales de la disciplina, como la concepción de cultura y su vinculación a la economía y la política, a los procesos de integración y diferenciación social, a la formación de redes y comunidades, la reconfiguración de clases sociales, etc. También es un tema sobresaliente porque cuestiona la pertinencia de la antropología para tratar, por sí sola, las prácticas y procesos de producción, circulación y consumos culturales, lo que pone de relieve la necesidad de la colaboración transdisciplinaria con campos como la economía, la mercadotecnia, la sociología, las políticas públicas, el urbanismo e incluso la administración pública o de empresas. A la vez, el tema plantea un reto metodológico importante respecto a las técnicas e instrumentos más adecuados para realizar investigación empírica, a partir del supuesto de que no hay una única estrategia posible para estudiarlo. Para conciliar, por ejemplo, la frialdad de los números con la imaginación antropológica, conviene combinar procedimientos clásicos con una etnografía más creativa y experimental.

Los estudios más actuales sobre consumos culturales conforman un campo disperso y desarticulado, integrado por esfuerzos aislados y proyectos sin continuidad, que no han cristalizado en un cuerpo conceptual sistematizado o un modelo teórico bien definido. Por lo mismo, tampoco ha sido fácil su reconocimiento oficial como línea de investigación dentro de la antropología y los estudios culturales. A la vez, existe gran vitalidad y una rica multiplicidad de acercamientos y vías de acceso a partir de la antropología, la economía, el urbanismo, la psicología o los estudios sobre políticas culturales e industrias creativas, entre otras disciplinas (Sunkel, 2006).

En años recientes se ha ampliado la concepción de las prácticas humanas como consumos culturales, que se ha extendido sobre todo a las prácticas vinculadas a las nuevas tecnologías en los medios de información y comunicación. La discusión se 
ha articulado con otros problemas antropológicos, como la vida cotidiana, el uso del espacio urbano, la participación política, los imaginarios y las culturas juveniles. Así, el estudio de los consumos culturales ha generado un interés transversal en buena parte del pensamiento antropológico contemporáneo (Rosas, 2012a). Cabe preguntarnos: ¿cuál es la especificidad de la mirada antropológica sobre el tema de los consumos culturales? ¿Qué se pregunta, en qué se enfoca? Éstas son algunas de las inquietudes que subyacen en la construcción de este ensayo.

El propósito de este texto es tomar el pulso, recorrer las tramas, delinear los contornos, atisbar los alcances, comprender los desafíos y trazar itinerarios de investigación en torno a los consumos culturales. El texto se divide en tres partes: i) panorama de autores, corrientes y conceptos fundamentales que han tratado el tema; ii) reflexión sobre el terreno específico de la difusión y el consumo de cine independiente - el tipo de consumo cultural que mejor conozco y más me interesa- a partir de un acercamiento a las redes, los actores que marcan tendencias y sus estrategias creativas para la difusión del cine independiente en México, y iii) planteamiento de un proyecto de investigación sobre públicos de cine independiente, con la idea de ponerlo en práctica en los próximos años. En suma, intentaré trazar un mapa del campo de los estudios sobre consumos culturales, articulado con una reflexión sobre los circuitos alternativos actuales para la difusión de cine independiente, para cerrar con una propuesta de investigación sobre los nuevos públicos de este cine.

\section{Panorama de los estudios sobre consumos culturales}

En un afán por recuperar ideas de autores clásicos, creo que podría considerarse a Marcel Mauss (2007) como uno de los precursores de la antropología económica y los estudios sobre producción, difusión y consumo cultural, tanto en lo material como lo simbólico. Su teoría del don, planteada en 1925, es esencial para comprender el contrato social implícito que regula la circulación, reciprocidad e intercambio de bienes, sentidos y significados en diferentes sociedades.

El tema de los consumos culturales, como se ha tratado en las últimas décadas, está muy emparentado con el interés por las políticas culturales. Proviene de una época de movimientos sociales y revoluciones culturales, a finales de la década de 1960, en la que se tenía la convicción, dentro de los estudios sobre cultura y comunicación, de que una mejor comprensión de los consumidores, públicos, asistentes o espectadores públicos y los consumos contribuiría al diseño de mejores políticas culturales. Impulsados por el ideal utópico de una democratización de los medios de comunicación, los estudios sobre políticas y consumos culturales replantearon de manera radical la relación entre los sujetos y las instituciones. Algunos autores se inspiraban en las ideas de Paulo Freire acerca de una comunicación para la libertad, no alienante, tolerante y plural, que promoviera el diálogo intercultural (Sunkel, 2006). Este espíritu crítico y transformador tuvo resonancias profundas no sólo entre pedagogos y comunicólogos, sino en esferas más amplias del pensamiento social. Pero el auge de los estudios sobre públicos y consumos también responde a las exigencias de competitividad y productividad de las industrias culturales insertas en un mercado global, regido por el libre comercio y las políticas económicas de signo neoliberal, como señala Ana Rosas Mantecón (2012a).

La consolidación del campo de los consumos culturales, a finales de la década de 1970, proviene sobre todo de los estudios culturales británicos, en particular de la escuela de Birmingham, en la que varios autores hicieron una relectura de filósofos marxistas clásicos, como Antonio Gramsci y Theodor Adorno, lo que dio pie a dos giros conceptuales o 
desplazamientos teóricos importantes: primero, de la construcción discursiva a la teoría de la decodificación (Morley, 1980); luego, de la decodificación a los análisis del consumo y a la etnografía de las audiencias (Morley, 1986; 1996). A la vez, se superó la idea del mensaje como estructura ideológica a favor de la teoría de la recepción crítica, según la cual los públicos no reciben los mensajes con pasividad, sino que los analizan, los retroalimentan y reaccionan, y dan cabida incluso a procesos de resistencia frente a los discursos hegemónicos (Sunkel, 2006).

Otra veta importante se desarrolló de manera paralela a partir de un diálogo con otro autor fundamental en esta genealogía: Pierre Bourdieu, cuyos conceptos, como "distinción" y habitus, serían retomados de manera crítica por autores latinoamericanos, como Néstor García Canclini, responsable en buena medida de introducir la discusión sobre la obra de Bourdieu al mundo de habla hispana (Nivón, 2012). Las ideas de Bourdieu (1988) sentaron las bases para desligar el tema de los consumos de una mera aproximación al ocio y el entretenimiento, a lo banal y el tiempo libre, para verlos como un componente esencial de la reproducción social y reconocer que ciertos objetos confieren estatus o se convierten en signos de distinción. Sin embargo, sus ideas resultan hoy anacrónicas e inaplicables a otros contextos culturales, en especial para las sociedades urbanas latinoamericanas del siglo XXI.

Los principales puntos de ruptura con el pensamiento de Bourdieu tienen que ver, a grandes rasgos, con que sugiere que las clases altas tienen un mayor consumo cultural, y por ende, poseen mayor cultura que las clases bajas, que se limitan a copiar y reproducir de manera disminuida los consumos y patrones culturales de las clases altas. De esto se puede desprender con facilidad la idea clasista de que la pobreza económica conlleva pobreza cultural, que identifica la cultura con las elites y la ignorancia con lo popular. En las megaurbes latinoamericanas contemporáneas queda claro que la relación entre consumo cultural y clases sociales es mucho más compleja de lo que plantea Bourdieu. No es que las clases bajas tengan menos cultura, sino que tienen otro tipo de acceso y consumo cultural. Más que copiar y reproducir la cultura de las elites hegemónicas, en la cultura popular surge una contracultura rica, movimientos de subversión y resistencia, procesos de diversificación de los gustos y los hábitos de consumo, con nuevas formas de producción, circulación y recepción de la cultura (García Canclini, 2006).

En la década de 1990, hubo en Latinoamérica una renovación de la discusión sobre consumos culturales, "lasinvestigaciones sobrelas prácticas culturales de los públicos respondieron también a una cierta utopía de los estudios culturales y a la efervescencia de las demandas sociales y políticas que pugnaban por una mayor democratización" (Rosas, 2012a: 3). Dos autores fundamentales en la construcción teórica del tema, Néstor García Canclini y Jesús Martín Barbero, introdujeron cambios conceptuales de fondo. Con ellos, se consolidó la concepción del consumidor como un sujeto activo - no un consumidor pasivo- que negocia, se apropia y produce sentidos y significados, y se desplazó la idea de un público homogéneo "en singular", a favor de la de públicos "en plural”, heterogéneos y diversos. Dos autores, Guillermo Sunkel (2006) y Germán Rey (2008), han hecho excelentes recuentos de los estudios aplicados en varios países latinoamericanos, en un esfuerzo por brindar una visión de conjunto y transversal de las dinámicas de consumo en la región.

Barbero se incorporó a la discusión a partir de su interés por las culturas populares y su propuesta de repensar la comunicación desde abajo. Los sujetos populares construyen sentidos y significados diferentes de los propuestos por la cultura hegemónica y los dispuestos por las industrias y las políticas culturales. Para él, comunicación es igual a interacción e intercambio intersubjetivo: 
Investigar el consumo cultural significa rescatar la creatividad de los sujetos, la complejidad de la vida cotidiana, el carácter interactivo y lúdico de la relación de los usuarios con los medios. Y para ello desplazar las fronteras entre disciplinas y estrategias metodológicas, integrando encuestas con indagación etnográfica, discusión en grupo con relatos de vida (Barbero, citado en Sunkel, 2006: 68).

En sintonía con estas ideas, García Canclini ha puesto el acento en cómo las culturas populares y las clases subalternas seleccionan, combinan y resignifican elementos de los discursos, los medios y las ofertas culturales hegemónicas para formar un bricolage. También pone de manifiesto la necesidad de la transdisciplina entre economía, antropología, sociología y ciencias de la comunicación, para tratar de manera más adecuada estos fenómenos. Para García Canclini, los estudios sobre consumos culturales pueden ser un espacio a partir del cual se entiende el significado de la modernización y se comprenden mejor los mecanismos de inclusión y exclusión social:

El estudio del consumo cultural aparece, así, como un lugar estratégico para repensar el tipo de sociedad que deseamos, el lugar que tocará a cada sector, el papel del poder público como garante de que el interés público no sea despreciado. Conocer lo que ocurre en los consumos es interrogarse sobre la eficacia de las políticas, sobre el destino de lo que producimos entre todos, sobre las maneras y las proporciones en que participamos en la construcción social del sentido (García Canclini, citado en Sunkel, 2006: 95).

Con la revolución digital y las nuevas tecnologías de comunicación e información, sobre todo desde el surgimiento de internet y la convergencia digital, aparece un tipo distinto de consumidor. Las personas no sólo consumen, también opinan, participan, generan insumos, son usuarios y emisores a la vez, públicos y productores. En los nuevos medios digitales se reduce la distancia entre producir y consumir, y surge la figura de los "prosumidores" (García Canclini, 2007). Por otra parte, de manera paulatina, se ha sustituido el término "consumo" por el de "acceso", y la discusión en general se ha desplazado hacia la noción de "participación cultural", para reconocer un sujeto activo que elige, se apropia, negocia, interactúa y ejerce su creatividad.

Un giro decisivo en el tratamiento del tema de los consumos culturales ocurrió cuando se le vinculó con la noción de territorio, en particular con el espacio y la cultura urbana; cuando se planteó estudiar la especificidad del consumo en las ciudades, en diferentes escalas, a partir de sus fragmentos y diversidades. Uno de los aportes más importantes en este sentido fue la idea de que a partir de la lógica de los medios de comunicación y los consumos culturales podemos reconceptualizar el espacio, las dinámicas e intercambios que definen la cultura urbana (García Canclini y Piccini, 1993).

García Canclini y Rosas Mantecón (2005), en su artículo "Políticas culturales y consumo cultural urbano", parten de la premisa de que la revolución tecnológica de la imagen digital e internet están generando nuevas modalidades urbanas de producción, circulación y consumo de cultura y una reconfiguración radical de los circuitos de comunicación audiovisual. Un hallazgo tan importante como inesperado fue la constatación de que en la era de la convergencia digital, lejos haber un proceso de democratización de los medios de comunicación, las brechas y contrastes se acentúan, el nuevo orden electrónico trae mayor desigualdad (Rosas, 2012b).

A partir del desarrollo de este campo de estudios, es posible ensayar una caracterización renovada del concepto de consumo cultural, más operativo y adecuado para las culturas contemporáneas. De manera sintética, se refiere al conjunto de prácticas de relación, interacciones y transacciones de los 
públicos con los bienes, mensajes y servicios culturales, así como con los medios de comunicación, de producción de sentidos y significados. No sólo son formas de explicarnos el mundo, sino estrategias o dispositivos por medio de los cuales actuamos e incidimos en la realidad. Para comprender a cabalidad la noción de consumo cultural, de entrada, es importante recalcar que se trata de una noción formada por racionalidades de diversa índole: económicas, políticas y simbólicas. De aquí que sea necesario, primero que nada, trascender sus acepciones exclusivamente instrumentalistas, conductistas o economicistas. Desde una perspectiva antropológica, el consumo no sólo se refiere a la mera satisfacción de necesidades básicas materiales con ciertos bienes, productos o mensajes. También hay que reconocer plenamente su dimensión simbólica (Rosas, 2012a).
En este sentido, en cuanto al uso del adjetivo "cultural", podemos preguntarnos si no todo consumo es cultural, si hay acaso un consumo que no lo sea. De acuerdo con el planteamiento de García Canclini, el calificativo se justifica por la autonomía que ha cobrado en la modernidad la esfera de la cultura y las artes. Pero sobre todo resulta apropiado poner énfasis en que son culturales los consumos en los que prevalece o predomina la dimensión simbólica sobre lo material, en los que el valor simbólico está por encima del valor de uso o de cambio (García Canclini, citado en Sunkel, 2006: 89).

García Canclini plantea varios aspectos esenciales de la noción de consumo: es tanto un factor de disputa, diferenciación, distinción o exclusión, como un sistema de comunicación, una forma de sociabilidad que genera empatía, así como un proceso ritual (García Canclini, citado en Sunkel, 2006). El

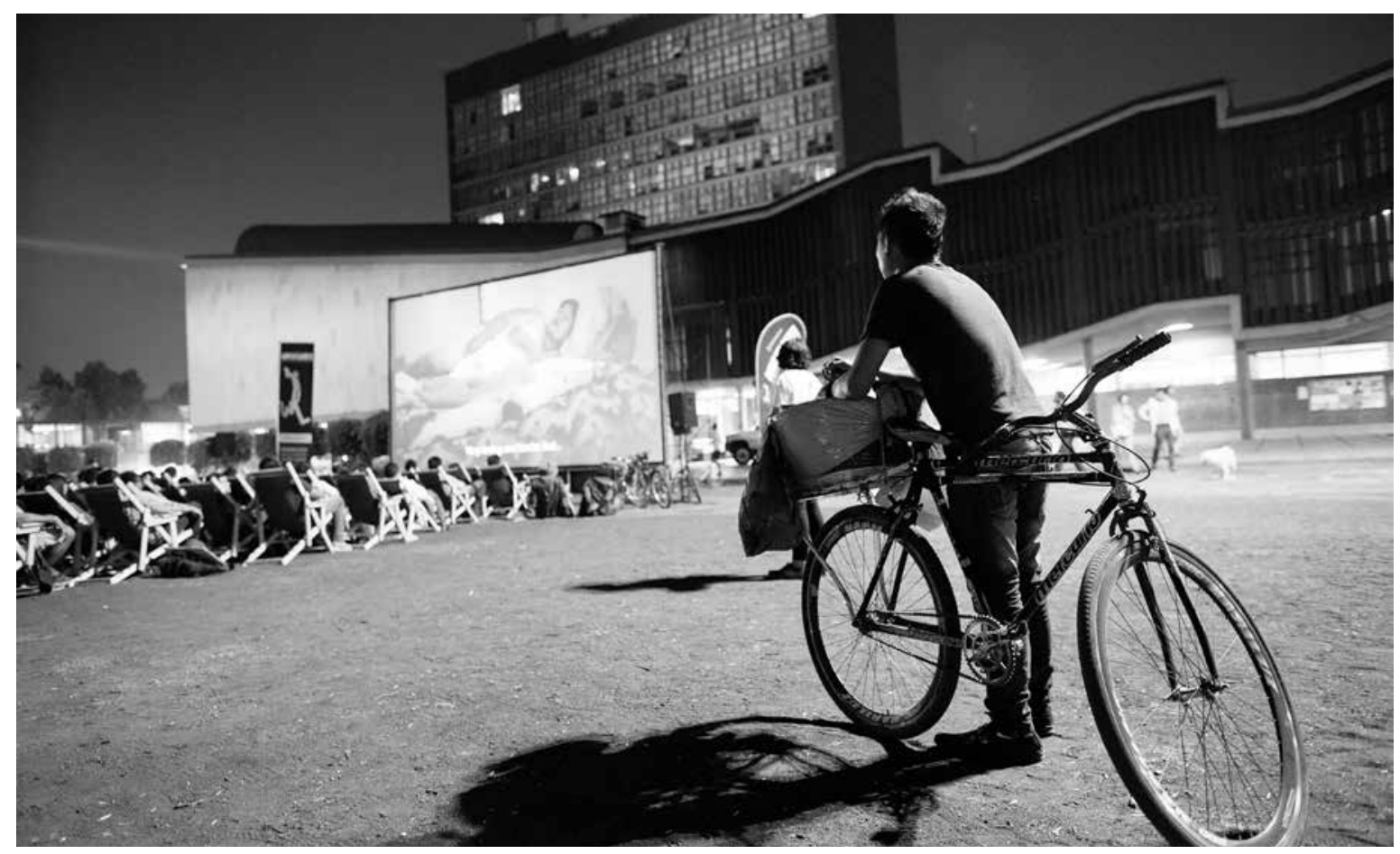

Delia MARTínez • Función al aire libre del documental Bellas de noche, de María José Cuevas, en Ambulante, Gira de Documentales. Las Islas, Ciudad Universitaria, Ciudad de México, abril de 2016. 
consumo es un componente de identidad y alteridad que permite comprender mejor los procesos de diversificación cultural. Por ejemplo, es posible repensar la estructura social y la dinámica de clases a la luz de los consumos culturales y ya no sólo a partir de factores económicos o índices demográficos.

A final de cuentas, consumo es producción de sentido, como dice Barbero (2006). Representa un espacio para la formación de identidades y la integración de comunidades. Los consumos culturales nos permiten relacionarnos entre nosotros y con los otros, son nodos a partir de los cuales tejemos redes, formamos o desintegramos grupos, interactuamos e intercambiamos símbolos y significados; son modos de estar juntos, de establecer gustos e intereses en común, identidades compartidas, comunidades epistémicas y afectivas; son formas de tejer y mantener vivo lo social. Hay que dejar de ver el consumo como una cuestión de gustos personales individuales y reconocer su carácter de práctica colectiva, comunitaria. Como tales, son modos de relacionarnos, de convivir, de incluirnos o discriminamos, de establecer conflictos y discordias, son referentes a partir de los cuales establecemos encuentros y desencuentros interculturales. También es importante destacar la dimensión política del consumo: los significados y bienes culturales también condensan, reactivan y transportan información, opiniones, valores, consensos, posturas políticas, luchas, movimientos o subversiones. Es decir, por medio del consumo cultural circula también el poder en sus múltiples expresiones y representaciones.

Por último, otro aspecto del giro latinoamericano y de las nuevas tendencias en los estudios sobre consumos culturales es el interés por la carga afectiva involucrada en la recepción, ligado a la llamada antropología de las emociones y los sentidos. Desde Lectores, espectadores e internautas, García Canclini (2007) señalaba que el consumo cultural también provoca reacciones y transformaciones en los sujetos en un nivel más primordial de la experiencia humana. Llamaba la atención sobre la dimensión estética — soslayada por la investigación tradicional-, el carácter sensorial y el placer corporal que conlleva el consumo cultural.

\section{Nuevas redes para la difusión del cine independiente}

En este apartado expongo con brevedad y reflexiono sobre los hallazgos de un estudio sobre estrategias creativas para la difusión del cine independiente en la Ciudad de México; una etnografía de varios festivales de cine y cineclubes que elaboré en fechas recientes con Claudine Cyr, como parte de un proyecto de investigación más amplio sobre jóvenes creativos y redes culturales, coordinado por Néstor García Canclini (Zirión y Cyr, 2014). Por el tema, el enfoque y la metodología, esta experiencia es representativa de los estudios actuales sobre consumo cultural en México. Se enfoca en las nuevas formas de circulación de la cultura audiovisual en las ciudades contemporáneas.

La transición del siglo XX al XXI trajo consigo cambios radicales en los mundos del cine: cómo se hace, quiénes lo hacen, cómo se mira, quiénes lo vemos, entre otros aspectos. A la mitad de la segunda década del nuevo siglo apenas empezamos a entender el profundo impacto de estas transformaciones globales que responden a fenómenos transversales, por ejemplo, la revolución de las tecnologías digitales, y también adoptan expresiones singulares, peculiaridades locales y características únicas según su contexto particular. Desde esta perspectiva, y con una mirada etnográfica, se exploran las reconfiguraciones recientes de la cultura audiovisual en México, a partir de lo que ocurre en sus márgenes y vanguardias. El principal interés se centra en las estrategias creativas de varios colectivos formados en su mayoría por jóvenes, que generan iniciativas y buscan alternativas para la distribución y exhibición del cine independiente. 
En los últimos diez años, el cine independiente y los circuitos alternativos han modificado de manera importante sus lógicas de consumo y circulación. En la Ciudad de México en específico, se han hecho visibles diversas propuestas ciudadanas para la difusión y promoción del cine documental, festivales como Ambulante, DocsMX, Festival de la Memoria, Festival Internacional de Cine de la Universidad Nacional Autónoma de México (FICUNAM) y Contra el Silencio Todas las Voces; organizaciones como Circo 2.12 y La Casa del Cine; cineclubes como Cinekiubs o Cineclub Bravo, por mencionar sólo algunos. Sin duda, para comprender el escenario emergente y las nuevas formas de difusión de la cultura cinematográfica, es necesario estudiar la experiencia de estas iniciativas. ¿Cuál es su lógica de trabajo y organización? ¿Quiénes las dirigen? ¿Cómo subsisten, qué criterios de selección tienen, qué dificultades enfrentan?

En el caso de México y otros países latinoamericanos, es posible encontrar cualidades en común que caracterizan a todos esos "otros cines", microcines, cines periféricos o alternativos, como el cine de arte, de autor, experimental u otros géneros, como la animación, el cine científico, político, periodístico o etnográfico. Estos subgéneros comparten una condición marginal y una actitud crítica respecto al cine hegemónico comercial y con frecuencia se les considera parte de la vanguardia artística. Sin embargo, existe un factor clave: el cine independiente por lo regular se encuentra serios obstáculos estructurales para su difusión óptima. Su denominación como "independiente" no sólo se refiere al tipo de contenido, al poco presupuesto o la libertad creativa de una determinada producción audiovisual, sobre todo apunta a la capacidad restringida para conectar con sus audiencias esperadas.

En este escenario, los festivales y cineclubes posibilitan la exhibición de una diversidad de géneros y formatos cinematográficos que por lo general no se distribuye ni reproduce. En estas redes de espacios alternos de difusión, con ayuda de las nuevas tecnologías de la información y comunicación, este cine marginal, pero quizá más libre y liberador, se extiende por todo el mundo, y sin dejar de ser marginal, se globaliza (Zirión y Cyr, 2014).

En este panorama, cabe preguntar: ¿cómo es que aparecen cada vez más emprendimientos alrededor de la difusión del cine independiente y cómo pueden subsistir económicamente? La mayoría de los proyectos operan con recursos bastante limitados, situación que compensan con ingenio y creatividad. Algunos proyectos culturales encaran dificultades económicas que desafían su viabilidad una y otra vez; son parte de los nuevos sectores creativos de la economía global que se caracterizan por ser "crónicamente inestables" (Rowan, 2010: 45). Los ingresos de la taquilla resultan insuficientes, de hecho, gran parte de los eventos y actividades que organizan estos festivales y cineclubes son gratuitos. La autosustentabilidad económica de estas iniciativas culturales está muy lejos de ser factible.

En general, estos emprendimientos logran su continuidad por medio de las contribuciones directas o en especie de patrocinadores públicos o privados. Aprovechan recursos de múltiples y diversas fuentes, tanto secretarías de cultura de los gobiernos de los estados, entidades federales y embajadas, como de empresas y establecimientos a cambio de visibilidad o publicidad durante los eventos. Existe una amplia gama de visiones y discursos por parte de estas iniciativas, entre la visión empresarial dispuesta a entrar en la lógica del mercado y la publicidad, y una posición más apegada a su espíritu independiente, de carácter social, civil y solidario.

En la base de los festivales y cineclubes siempre hay equipos de personas que ensayan nuevas formas de organización para trabajar juntas. En general, los colectivos son muy maleables, empezando por el número y la edad de los integrantes. Los festivales operan buena parte del año con un núcleo reducido de gente, que se incrementa de manera 
paulatina con colaboradores ocasionales, independientes, prestadores de servicio social y voluntarios. A veces hay una división clara del trabajo, puestos y jerarquías, aunque en la práctica cotidiana predomina un esquema de trabajo en red, por áreas, más horizontal. La flexibilidad caracteriza la dinámica de estos colectivos en cuanto a horarios y lugares de trabajo, en la asignación de puestos y la división de labores. Las personas suelen trabajar sin horarios fijos y cumplir sus labores desde casa. En este sentido, la tecnología facilita mucho la flexibilidad y el trabajo independiente.

Bajo la modalidad del trabajador independiente o freelance, con contratos informales, temporales o por obra determinada, los miembros de estos equipos realizan múltiples actividades y se involucran en áreas y etapas de trabajo diversas. Estos trabajadores jóvenes creativos deben ajustar su vida a horarios, calendarios e ingresos inestables, a la falta de seguridad social e incertidumbre ante un futuro a corto plazo. Aunque para algunos ser flexible significa mayor libertad e independencia, en el fondo la línea divisoria entre flexibilidad y autoexplotación se torna cada vez más delgada y borrosa.

La difusión del cine independiente, en definitiva, no es un gran negocio y no es una opción laboral muy redituable en términos económicos: nadie se enriquece de ello. ¿Cuáles son entonces los valores asociados a este tipo de industrias creativas? En los discursos de estos emprendedores o trendsetters — creadores de tendencias-, siempre hay un orgullo especial por pertenecer a estos emprendimientos. Esto parece tener un alto valor simbólico, que brinda cierto prestigio o estatus social. Las actitudes oscilan entre un cierto "altruismo cultural", que se sustenta en el ideal de trabajar por amor al arte, y un "microactivismo", animado por el ideal de trabajar con la convicción de que el cine documental permite subvertir la hegemonía del cine comercial.

Al mismo tiempo, ha habido importantes transformaciones en el interior de cada festival,

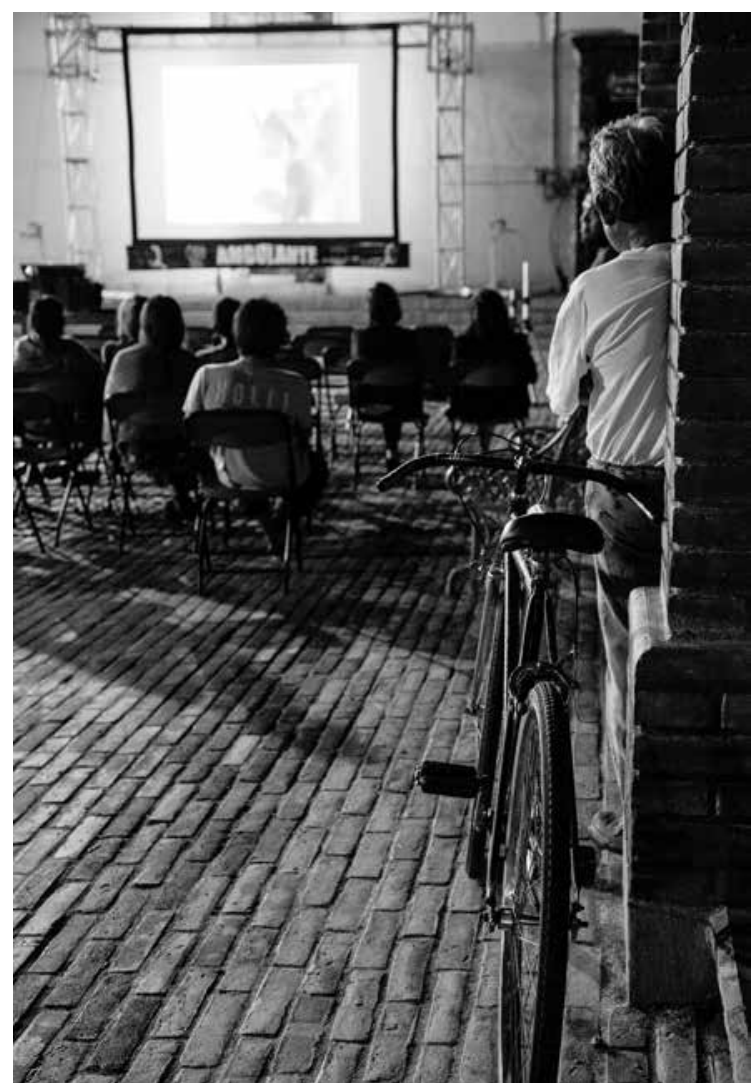

Delia Martínez - Función al aire libre de la película Redes, de Emilio Gómez Muriel y Fred Zinnemann, en Ambulante, Gira de Documentales. Centro de Teotitlán del Valle, Oaxaca, abril de 2014.

tanto en las más grandes como en las pequeñas iniciativas. En todos los casos, con el paso de los años, se han ido reinventando en cuanto a los componentes que ofrecen al público. Lejos de dedicarse sólo a la proyección de películas, los festivales en la actualidad organizan cada vez más actividades especiales, ensayan otras maneras de llegar al público: funciones al aire libre, en plazas públicas, autocinemas, secciones especializadas, retrospectivas, muestras paralelas, conferencias, foros académicos, concursos, talleres, becas, etcétera.

Existen varias experiencias y proyectos de colaboración entre festivales y cineclubes; se tejen redes que buscan exhibir cine en pequeños centros culturales en todo el país, a lo largo de todo el año. 
Sin duda, los festivales y cineclubes pueden y deben trabajar juntos. Una difusión óptima del cine independiente tendría que pasar por la buena colaboración y complementariedad entre salas comerciales, festivales y cineclubes. Pero las redes de colaboración, además de operar de manera local, pueden extenderse y volverse transnacionales. En todo esto, internet es fundamental, por los nuevos medios de comunicación y el trabajo a distancia por medio de plataformas, sitios y redes especializadas para festivales en línea. Además de estas tecnologías, de manera concreta, las redes pasan por las relaciones cara a cara entre personas; las amistades y los contactos personales no dejan de ser muy importantes en el medio del cine.

No sólo en el terreno del cine, sino en las industrias culturales en general, hay una marcada tendencia hacia la "festivalización de la cultura", que intenta condensar en un periodo corto lo más sobresaliente de una determinada área o especialidad artística o cultural. Así, toda actividad o expresión cultural, para sobrevivir, tiene que convertirse en una fiesta, en un evento público y mediático. Quizá esta "festivalización" haya sido necesaria para salir de una condición de asfixia ante una escasa diversidad en la oferta cinematográfica comercial. Sin duda, ha ayudado a apuntar los reflectores hacia otros cines y esto es de celebrarse, pero en el fondo, esperamos que sea sólo una etapa de transición hacia un modelo más permanente de difusión de la cultura audiovisual alternativa, que opere durante todo el año de manera autosustentable, sin dejar de ser independiente.

El cine independiente constituye un espacio alternativo de posibilidades, su exhibición genera y multiplica las oportunidades de reflexión, descubrimiento y transformación. En un país con una falta de educación considerable y un monopolio de las ideas por parte de dos grandes televisoras, cuya oferta cinematográfica se encuentra secuestrada por las grandes distribuidoras transnacionales, el cine puede cumplir una función crítica y pedagógica elemental. Estos espacios de libertad, encuentro y debate, como son las universidades públicas, los cineclubes comunitarios y los festivales de cine independiente, son fundamentales para la sociedad.

\section{Etnografía de los espectadores de cine independiente}

Desde hace ocho años, además de mi carrera como antropólogo y documentalista, me he desempeñado como programador en dos festivales de cine documental: DocsMX y Ambulante. Este último consiste en una gira de tres meses que lleva una selección de cine documental mexicano e internacional a varios estados de la República mexicana. Esta experiencia como curador de cine me ha permitido conocer de cerca e interactuar con una gran diversidad de públicos, espectadores de distintas edades, orígenes étnicos y culturales, estratos económicos, y de ámbitos rurales y urbanos. Ha sido interesante constatar, por ejemplo, que la recepción de una misma película puede ser diferente por completo en un centro cultural en San Cristóbal de Las Casas, Chiapas, en un Cinépolis en Morelia, Michoacán, en la Fábrica de Artes y Oficios (Faro) de Oriente, en la Ciudad de México, o en una función al aire libre en Playas de Tijuana.

Aprovecho esta experiencia directa para esbozar en este artículo algunos ejes para una investigación sobre consumo audiovisual fuera de los circuitos comerciales, un aspecto de la cultura contemporánea relativamente poco explorado desde una perspectiva antropológica. La propuesta es hacer un estudio etnográfico sistemático y a profundidad sobre los nuevos espectadores de cine independiente en México. Una investigación como ésta requeriría articular tres perspectivas antropológicas: la antropología urbana, la antropología visual y los estudios sobre gestión, políticas y consumos 
culturales, pero también sería necesario ampliar los horizontes transdisciplinarios del proyecto, incorporar especialistas y nociones de la comunicación social y política, la teoría y la historia del arte, y la psicología social, entre otras disciplinas afines. Un estudio de esta magnitud debería contar con financiamiento no sólo del Consejo Nacional de Ciencia y Tecnología (Conacyt), sino principalmente del Instituto Mexicano de Cinematografía (Imcine), el Consejo Nacional para la Cultura y las Artes (Conaculta), las secretarías de Cultura y de Educación Pública, o algún otro organismo público o privado que pueda respaldar el proyecto, toda vez que los resultados pueden ser de gran utilidad para varios sectores: festivales, programadores, autoridades responsables de las políticas culturales y urbanas, empresas exhibidoras y distribuidoras, incluso realizadores y productores pueden beneficiarse al conocer mejor el perfil de sus audiencias potenciales.

Antes de emprender este proyecto, habría que releer dos investigaciones fundamentales sobre consumo de cine en México. La primera, Los nuevos espectadores: cine, televisión y video en México, de García Canclini (1994), que analiza sobre todo las formas de consumo audiovisual doméstico, fuera de las salas de cine. A 20 años de su publicación, es pertinente actualizar la información y renovar la reflexión sobre los públicos de cine en México, rastrear las rupturas y continuidades a lo largo de dos décadas, estimar el impacto de las recientes revoluciones tecnológicas que han generado profundas transformaciones en la cultura audiovisual contemporánea, y revisar la congruencia de los instrumentos utilizados entonces para tratar los escenarios actuales. La segunda, contenida en los numerosos artículos de Rosas Mantecón, entre ellos "Las batallas por la diversidad: exhibición y públicos de cine en México" (2006), en el que analiza el impacto de las salas multiplex y el aumento del consumo y el crecimiento de la oferta de cine en términos de la cantidad de espacios de exhibición comercial, a la vez que revela una menor diferenciación del público — no es claro si estamos ante un proceso de democratización o de elitización - y confirma la dramática reducción de la diversidad de la oferta cinematográfica en las pantallas comerciales, que representa un lamentable empobrecimiento de nuestra cultura audiovisual.

Hay que destacar que en los estudios sobre públicos audiovisuales predominan las investigaciones de carácter cuantitativo, estadístico o demográfico. Es fácil saber cuánta gente fue a ver una película en un fin de semana, así como es común escuchar cifras sobre visitantes de museos, usuarios de internet, espectadores de cine, asistentes al teatro, etc. También suelen realizarse estudios sobre los perfiles de los espectadores: género, edad, nivel de escolaridad y de ingresos, lugar de residencia, etc. Como ejemplo, están los anuarios de información estadística que publica el Imcine. Sin embargo, no todos los sistemas de medición son tan confiables y no siempre se hacen del dominio público. Muchos provienen de las mismas empresas e industrias culturales, como parte de su investigación de mercado, con claros sesgos según sus intereses propios. Sin duda, los datos duros son imprescindibles, pero es importante que se recaben e interpreten de manera consistente. Hacen falta más y mejores cifras, y a partir de ellas, elaborar un análisis cualitativo y una reflexión teórica bien fundamentada. Ambos tipos de análisis — cuantitativo y cualitativo- son necesarios y complementarios por igual.

En este sentido, cabe apuntar algunas certezas acerca de los asistentes a los festivales de cine:

El público de los festivales es mayoritariamente joven, con un predominio notable de estudiantes universitarios. Según los reportes de resultados de Ambulante de 2012 y 2013, el 67\% de su público tiene entre 15 y 25 años, y el 50\% son estudiantes universitarios. Las funciones gratuitas o al aire libre atraen a un público muy amplio y diverso, desde estudiantes hasta los ancianos del barrio. El 
público de cine independiente que acude a los festivales sin duda está creciendo; por ejemplo, DocsDF ha duplicado su audiencia cada año desde su fundación en 2006; pasó de tener 6 mil espectadores en su primera edición, a 30 mil en la quinta, en 2010. Por su parte, en términos de público asistente, Ambulante aumentó 26\% de 2011 a 2012, y en total ha crecido $610 \%$ desde su primera edición hasta la octava en 2013 (Zirión y Cyr, 2014).

Más allá de las estadísticas, hay otras cuestiones cualitativas muy interesantes. Casi todos los proyectos de exhibición alternativa consideran que buena parte de su misión consiste en la formación de públicos. Sin embargo, no parece haber consenso respecto a qué representa o qué implica esta tarea, no queda claro si se trata de atraer nuevos espectadores o de informar mejor a los cautivos. En el fondo, hay una tensión entre concepciones diversas de público, una quizá más elitista y otra acaso más populista. Algunos emprendedores en el terreno de la difusión de cine coinciden en que su misión es atraer y reeducar a un público mal acostumbrado a consumir sólo televisión y cine comercial. Otros consideran que ya existe un público cultivado que deben atender, ante la estrecha oferta del cine comercial. En medio de estos polos se abre un extenso espectro de propuestas que delinean el panorama de la exhibición de cine independiente en la Ciudad de México.

Sin duda, las formas de consumir cine han cambiado mucho a partir de internet y las nuevas tecnologías de comunicación, en especial con la posibilidad de reproducir, compartir y descargar películas de manera digital. En países como México, donde la oferta de cine independiente mundial es reducida, muchos cinéfilos encuentran las películas que quieren ver en internet o en productos de la piratería. Hasta ahora han podido coexistir diversas formas de ver cine, que no necesariamente compiten ni se desplazan unas a otras. Los jóvenes cinéfilos contemporáneos bien pueden descargar una película de internet — de manera legal o ilegal-, comprar una película pirata afuera del metro para verla y luego regalarla, adquirir el disco original de sus títulos favoritos, conectarse a Netflix desde su celular, ir de vez en cuando al Cinépolis de una plaza comercial al estreno de una película hollywoodense, o bien, asistir con frecuencia a la Cineteca Nacional - y pagar su boleto con descuento para estudiantes - para ver un documental presentado en el marco de un festival; también puede mirar de reojo o con intermitencia una película en la televisión por cable de su casa, a la par del noticiero nocturno. Es central tener en cuenta este eclecticismo en el consumo audiovisual para comprender el perfil psicosocial de los nuevos espectadores: cómo construyen sentido y articulan discursos hegemónicos y contraculturales, descifran y reinterpretan significados entre innumerables canales y medios de comunicación oficiales, comerciales o contrahegemónicos, en medio de la compleja trama de la cultura digital que nos somete a un bombardeo incesante de símbolos, mensajes, imágenes y sonidos.

También es importante contemplar que el público aún busca en el cine vivir una experiencia colectiva, un encuentro con lo propio y lo diferente. Nada puede reemplazar la experiencia de ir al cine y ver una película en pantalla grande, en la oscuridad, junto a otras personas. La interacción humana entre los espectadores y la conexión con la película, la empatía, identificación, rechazo o extrañamiento que implica el acto de ir al cine sigue siendo un componente primordial del fenómeno cinematográfico, desde sus orígenes, a finales del siglo XIX, hasta la actualidad. Entre tantas transformaciones, este elemento cardinal de la experiencia cinematográfica se mantiene vigente.

¿Cómo estudiar con seriedad los nuevos consumos multimodales y los públicos eclécticos? ¿Cómo captar la multiplicidad de sus comportamientos, dentro y fuera de la sala de cine? En cuanto a los retos metodológicos que implica una investigación 
de esta naturaleza, es claro que conviene combinar estrategias y procedimientos, tradicionales y experimentales, cuantitativos y sobre todo cualitativos.

En general, la perspectiva metodológica derivada de la teoría del actor-red, de Bruno Latour (2009), me parece muy apropiada para hacer etnografía de los mundos contemporáneos. Algunos de los procedimientos sugeridos funcionarían a la perfección para el estudio que aquí se esboza, por ejemplo, seguir a los actores sociales, andar tras sus huellas, describir sus acciones e interacciones, rastrear sus conexiones y desconexiones, hacer caso de sus propias categorías, tratar de entender la realidad desde su posición en la constelación de vínculos con otros actores. Esta propuesta teóricometodológica me parece en particular apropiada para examinar un universo como el de los consumos culturales, conformado por circuitos, corrientes y flujos, actores en movimiento y redes en transformación constante.

Hacer antropología de públicos de cine implica, en un primer momento, hacer etnografía en la oscuridad, dentro de la sala, en el momento de la función, compartir el fenómeno cinematográfico, ser parte de la experiencia colectiva. Ser observador participante en una función significa también ser espectador, incluso cinéfilo. En mi opinión, resulta indispensable participar de la empatía o el sentimiento que despertó una película en una audiencia para describir la calidad de una función. Es importante estar atento a las reacciones del público en varios momentos de la película, notar las risas, los lamentos, sentir qué tan conectada está la gente con los personajes de la película. Hay que tomar nota de los comportamientos de los espectadores, detectar signos de aburrimiento, a los se quedan dormidos, revisan sus teléfonos o comen golosinas de manera compulsiva, así como a quienes se mantienen al filo de la butaca, transportados a otra dimensión, absortos, fuera de sí. En otro orden de preguntas, también habrá que tener en mente qué tanto influye la calidad técnica de la proyección y qué impacto tienen los formatos en la recepción del público.

Además de esta singular etnografía, el proyecto requeriría hacer encuestas y entrevistas con los espectadores, conversar con ellos sobre la película y su experiencia de consumo, de preferencia al salir de la sala, con la vivencia fresca, para conocer los motivos por los que asistió a ver esa película, su opinión, sus críticas, las emociones que le causó y la importancia que le confiere, entre otras cuestiones. Queda claro el carácter cualitativo de este estudio, en tanto le otorga al espectador la capacidad de hacer crítica y análisis cinematográfico, toma en cuenta su parecer, sus interpretaciones y reflexiones a partir de la película, cuestiones subjetivas, de gustos y preferencias personales.

\section{Epílogo}

Para cerrar, quisiera relatar una anécdota que me parece reveladora de algunos problemas discutidos en este escrito. En 2013, fui invitado junto con Mara Fortes a programar una muestra de cine mexicano contemporáneo para el Museo Nacional de Arte Reina Sofía, en Madrid, España. El ciclo México inminente estuvo integrado por 12 películas que se proyectaron en el auditorio del Edificio Sabatini del Museo, del 17 de julio al 30 de agosto (Zirión y Fortes, 2013). ${ }^{1}$

1

Algunos títulos de las películas que se incluyeron en la muestra fueron: Fecha de caducidad (2011), de Kenya Márquez; Matar extraños (2013), de Nicolás Pereda y Jacob Schulsinger; Penumbra (2011), de Eduardo Villanueva; El alcalde (2012), de Diego Enrique Osorno, Emiliano Altuna y Carlos F. Rossini; Cuates de Australia (2012), de Everardo González; Los que se quedan (2008), de Juan Carlos Rulfo; Post Tenebras Lux (2012), de Carlos Reygadas; Después de Lucía (2012), de Michel Franco; Quebranto (2013), de Roberto Fiesco; Malaventura (2011), de Michel Lipkes; Un mundo secreto (2013), de Gabriel Mariño; El lenguaje de los machetes (2011), de Kyzza Terrazas. 


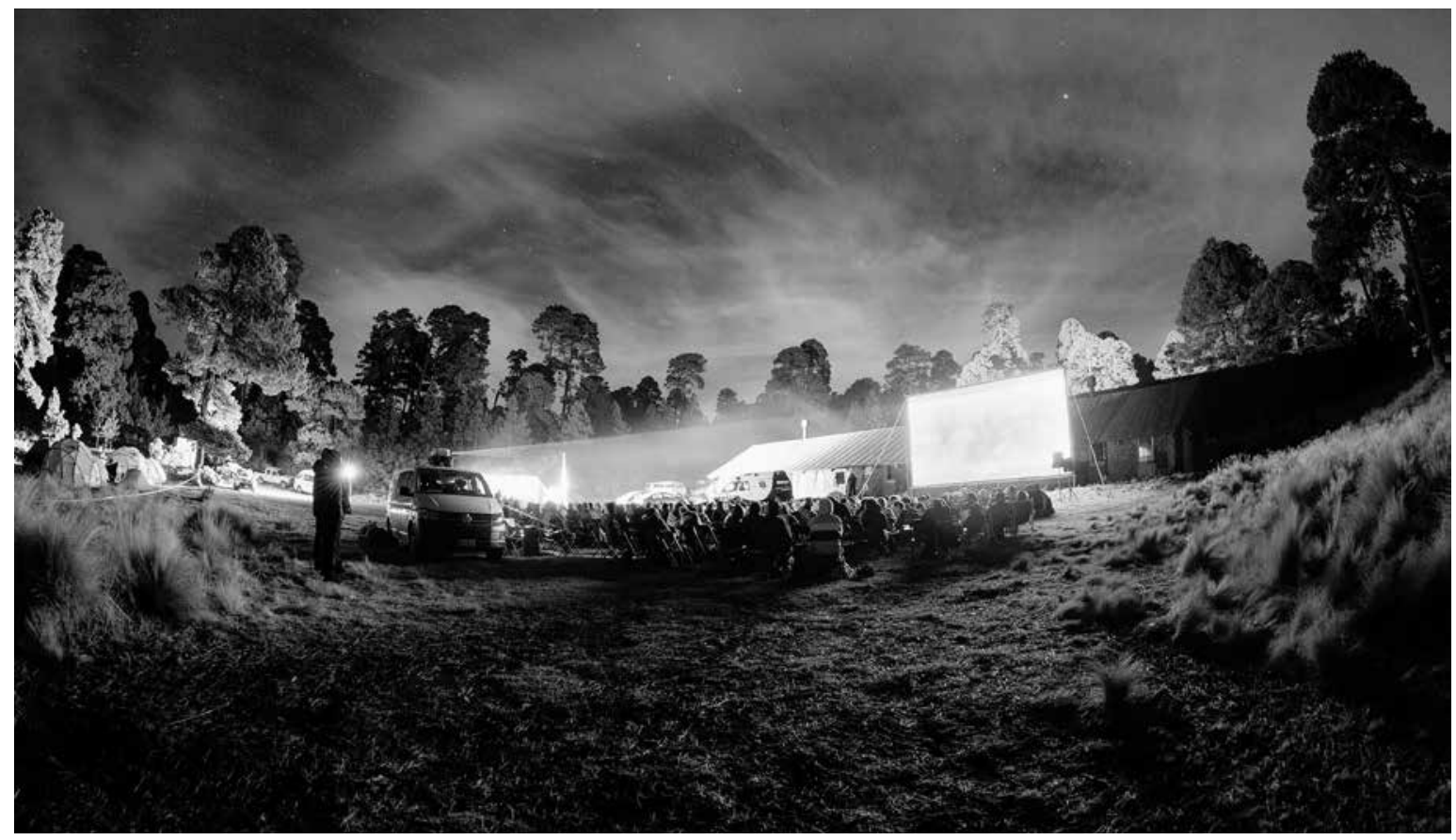

DeliA MARTíneZ - Función al aire libre del documental Sherpa: héroes del Everest, de Jennifer Peedom, en Ambulante, Gira de Documentales. Nevado de Toluca, Estado de México, abril de 2016.

De acuerdo con el jefe de Actividades Culturales del Museo, la invitación respondió al gran interés que siempre ha habido, y que se ha incrementado en los últimos años, no sólo en España sino en varios países europeos, por conocer más a profundidad el cine mexicano. Durante los meses de verano, el Museo se convirtió en una ventana abierta para que los visitantes se asomaran a la filmografía mexicana reciente, para ver las películas que han ganado premios en festivales internacionales, responsables de la buena fama de nuestro cine, así como documentales relevantes, pero difíciles de ver, o un cine más experimental y autoral, dirigido al circuito de festivales, pero con escasa circulación. El primer reto como curadores consistió en programar películas para un público que no conocíamos de manera directa, sobre todo jóvenes madrileños y turistas de todo el mundo que asisten al Museo. Además, teníamos el desafío de elegir títulos que fueran representativos de la producción de cine mexicano contemporáneo y la responsabilidad de proyectar una imagen del país hacia el exterior. La curiosidad y avidez por el cine mexicano entre el público europeo se confirmó con el éxito del ciclo en términos de la nutrida asistencia y buena retroalimentación que se registró en la mayoría de las funciones.

A los pocos meses, recibimos la propuesta de replicar el ciclo en el Centro de Cultura Digital (CCD) en la Ciudad de México. Desde luego, nos entusiasmó la posibilidad de ver cómo el público mexicano recibía este ciclo. Fue curioso que la gestión y realización de esta segunda ronda de exhibiciones en nuestra propia ciudad tomara mucho más tiempo y esfuerzo que la primera, que sucedió al otro lado del océano y fue coordinada a distancia, de manera virtual. Resultó irónico que, dado que la curaduría había sido comisionada por el Museo, para replicar el ciclo fue necesario negociar, pagar derechos y dar crédito al Museo. Es decir, técnicamente tuvimos que importar de España a México una muestra de cine mexicano. Para llevarla a cabo, hubo que sortear 
obstáculos administrativos y trabas burocráticas. El presupuesto del CCD con el que se pagarían los derechos de proyección estaba asegurado, pero no contarían con él sino hasta varios meses después. Para agilizar los trámites, el festival Ambulante se sumó a la organización, para que por medio de su asociación civil se hicieran los pagos y trámites legales, pero ello implicó una serie de aspectos fiscales no contemplados en un principio. Por éstos y otros asuntos, la fecha prevista para la muestra tuvo que posponerse un par de veces, hasta que el ciclo pudo llevarse a cabo en la Ciudad de México a principios de 2014, copresentado por el Museo Reina Sofía, el CCD, en colaboración con Ambulante, Gira de Documentales. Después de tantas peripecias, resultó que la asistencia fue bajísima, la muestra pasó casi desapercibida para el público mexicano, salvo en los casos en que los directores estuvieron presentes en las funciones.

¿A qué se debe el éxito de una muestra de cine nacional en un país extranjero y su fracaso en el país de origen? Sin duda, es una cuestión compleja en la que entran en juego múltiples factores. Es obvio que el CCD no tiene la misma concurrencia que el Museo Reina Sofía, pero además, ¿fue un problema de planeación y mala difusión? ¿Influyeron la historia y la ubicación de la sede? ¿Quizá en esos días había una sobreoferta de eventos cinematográficos en la ciudad? Más allá de lo anecdótico, este episodio podría ser un estudio de caso para analizarlo a la luz de las categorías y los debates en torno a los consumos culturales expuestos en la primera parte de este escrito. Es un ejemplo muy ilustrativo de la manera en que se tejen redes para la exhibición alternativa de cine independiente, como las descritas en la segunda parte. En relación con la propuesta de investigación esbozada en el tercer apartado, este caso hace patente la necesidad de conocer y entender mejor las dinámicas de los públicos y el perfil de los nuevos espectadores de cine en las urbes contemporáneas. D

\section{Bibliografía}

Barbero, Jesús Martín, 2006, "Recepción de medios y consumo cultural: travesías", en Guillermo Sunkel (coord.), El consumo cultural en América Latina. Construcción teórica y líneas de investigación, Convenio Andrés Bello, Bogotá, pp. 47-71.

Bourdieu, Pierre, 1988, La distinción, Taurus, Madrid.

García Canclini, Néstor, 1994, Los nuevos espectadores: cine, televisión y video en México, Instituto Mexicano de Cinematografía/Consejo Nacional para la Cultura y las Artes, México.

—_ 1995, Consumidores y ciudadanos. Conflictos multiculturales de la globalización, Grijalbo, México.

—_ 1998, Cultura y comunicación en la Ciudad de México, Grijalbo/Universidad Autónoma Metropolitana, México.

—_, 2004, Diferentes, desiguales y desconectados. Mapas de la interculturalidad, Gedisa, Barcelona.

__, 2005, La antropología urbana en México, Consejo Nacional para la Cultura y las Artes/Universidad Autónoma Metropolitana/Fondo de Cultura Económica, México.

—_ 2006, "El consumo cultural: una propuesta teórica”, en Guillermo Sunkel (coord.), El consumo cultural en América Latina. Construcción teórica y líneas de investigación, Convenio Andrés Bello, Bogotá, pp. 72-95.

_ 2007, Lectores, espectadores e internautas, Gedisa, Barcelona.

García Canclini, Néstor, Francisco Cruces y Maritza Urteaga (coords.), 2012, Jóvenes, culturas urbanas y redes digitales, Fundación Telefónica/ Ariel, Barcelona y Madrid.

García Canclini, Néstor y Mabel Piccini, 1993, El consumo cultural en México, Consejo Nacional para la Cultura y las Artes, México.

García Canclini, Néstor y Ernesto Piedras Feria (coords.), 2013, Jóvenes creativos. Estrategias y redes culturales, Universidad Autónoma Metropolitana/Fondo Nacional para la Cultura y las Artes/Juan Pablos, México.

García Canclini, Néstor y Ana Rosas Mantecón, 2005, "Políticas culturales y consumo cultural urbano”, en Néstor García Canclini (coord.), en La antropología urbana en México, Consejo Nacional para la Cultura y las Artes/Universidad Autónoma Metropolitana/Fondo de Cultura Económica, México, pp. 168-190. 
Latour, Bruno, 2009, Reensamblar lo social. Una introducción a la teoría del actor-red, Manantial, Buenos Aires.

Mauss, Marcel, 2007, Ensayo sobre el don. Forma y función del intercambio en las sociedades arcaicas, Katz, Madrid.

Morley, David, 1980, The Nationwide Audience, British Film Institute, Londres.

, 1986, Family Television, Comedia/Routledge, Londres.

, 1996, Televisión, audiencias y estudios culturales, Amorrortu, Buenos Aires.

, 2007, Media, Modernity and Technology. The Geography of the New, Routledge, Londres.

Morley, David y Kevin Robins, 1995, Spaces of Identity. Global Media, Electronic Landscapes and Cultural Boundaries, Routledge, Londres.

Nivón, Eduardo, 2012, "Una vida de trabajo, disciplina y arte", en Eduardo Nivón (coord.), Voces híbridas, reflexiones en torno a la obra de García Canclini, Universidad Autónoma Metropolitana/Siglo XXI Editores, México, pp. 15-30.

Rey, Germán, 2008, Las tramas de la cultura, Convenio Andrés Bello, Bogotá.

Rosas Mantecón, Ana, 2006, “Las batallas por la diversidad: exhibición y públicos de cine en México”, en Guillermo Sunkel (coord.), El consumo cultural en América Latina. Construcción teórica y líneas de investigación, Convenio Andrés Bello, Bogotá, pp. 318-341.

, 2012a, "Presentación”, en Alteridades, año 22, núm. 44: Consumos culturales en América Latina, pp. 3-8.

__ 2012b, "Itinerarios de un viajero por el consumo cultural”, en Eduardo Nivón (coord.), Voces hibridas, reflexiones en torno a la obra de García Canclini, Universidad Autónoma Metropolitana/Siglo XXI Editores, México, pp. 138-165.

, 2012c, "Públicos de cine en México", en Alteridades, año 22, núm. 44: Consumos culturales en América Latina, pp. 41-58.

Rowan, Jaron, 2010, Emprendizajes en cultura. Discursos, instituciones y contradicciones de la empresarialidad cultural, Traficantes de Sueños, Madrid.

Sunkel, Guillermo (coord.), 2006, El consumo cultural en América Latina. Construcción teórica y líneas de investigación, Convenio Andrés Bello, Bogotá.

Ugalde, Víctor, 1998, "Panorama del cine en México: cifras y propuestas”, en Estudios Cinematográficos, año 4, núm. 14, pp. 45-59.

—_ 2000, "El TLC: la otra conquista”, en Javier Esteinou Madrid, Víctor Osorio y Enrique E. Sánchez (coords.), Industrias culturales y TLC: impactos y retos de la apertura, Fronteras Comunes/Red Mexicana de Acción frente al Libre Comercio/Sociedad General de Escritores de México, México, pp. 85-105.

Urteaga, Maritza, 2011, La construcción juvenil de la realidad. Jóvenes mexicanos contemporáneos, Juan Pablos/Universidad Autónoma Metropolitana-Iztapalapa, México.

Zirión, Antonio y Claudine Cyr, 2014, "Circuitos alternos: nuevas redes y estrategias creativas para la difusión del cine documental en México", en Abel Muñoz y Claudia Curiel (coords.), Reflexiones sobre cine mexicano contemporáneo: documental, Cineteca Nacional/Consejo Nacional para la Cultura y las Artes, México, pp. 23-35.

Zirión, Antonio y Mara Fortes, 2013, "México inminente. Imaginarios de la insurgencia en el cine contemporáneo", texto de los programadores, Museo Nacional de Arte Reina Sofía, Madrid. Disponible en línea: <http://www.museoreinasofia.es/sites/default/files/actividades/pro gramas/texto_programadores_0.pdf>.

\section{Filmografía}

Fiesco, Roberto (dir.), 2013, Quebranto, Mil nubes/Consejo Nacional para la Cultura y las Artes/Instituto Mexicano de Cinematografía/ Universidad Nacional Autónoma de México-Centro Universitario de Estudios Cinematográficos, México.

Franco, Michel (dir.), 2012, Después de Lucía, Pop Films/Filmadora Nacional/Lemon Films/Stromboli Films/Lucia Films/Trebol Stone, México. González, Everardo (dir.), 2012, Cuates de Australia, Artegios, México.

Lipkes, Michel (dir.), 2011, Malaventura, Balero Films/Iron Age Pictures/Videocine, México.

Mariño, Gabriel (dir.), 2013, Un mundo secreto, Sobrevivientes Films/Bambú Audiovisual/ Agencia sHA, México.

Márquez, Kenya (dir.), 2011, Fecha de caducidad, Puerco Rosa, México.

Osorno, Diego Enrique, Emiliano Altuna y Carlos F. Rossini (dirs.), 2012, El alcalde, Bambú Audiovisual, México.

Pereda, Nicolás y Jacob Schulsinger (dirs.), 2013, Matar extraños, Interior13/DOX:LAB/CPH:DOX, México.

Reygadas, Carlos (dir.), 2012, Post Tenebras Lux, No Dreams Cinema/Mantarraya Producciones/Le pacte/Topkapi Films, México, Francia,

Alemania y Holanda.

Rulfo, Juan Carlos y Carlos Hagerman (dirs.), 2008, Los que se quedan, Fundación BBva Bancomer/La sombra del guayabo, México.

Terrazas, Kyzza (dir.), 2011, El lenguaje de los machetes, Fi Ga Films, México

Villanueva, Eduardo (dir.), 2011, Penumbra, Hubert Bals Fund, México. 